\title{
Transcript levels of Toll-Like receptors 5, 8 and 9 correlate with inflammatory activity in Ulcerative Colitis
}

\author{
Fausto Sánchez-Muñoz ${ }^{1,2,6}$, Gabriela Fonseca-Camarillo², Marco A Villeda-Ramírez ${ }^{2}$, Elizabeth Miranda-Pérez², \\ Edgar J Mendivil ${ }^{2}$, Rafael Barreto-Zúñiga ${ }^{3}$, Misael Uribe ${ }^{2,4}$, Rafael Bojalili ${ }^{5,6}$, Aarón Domínguez-López² and \\ Jesús K Yamamoto-Furusho ${ }^{2 *}$
}

\begin{abstract}
Background: Dysregulation of innate immune response by Toll-Like Receptors (TLRs) is a key feature in Ulcerative Colitis (UC). Most studies have focused on TLR2, TLR3, and TLR4 participation in UC. However, few studies have explored other TLRs. Therefore, the aim of this study was to evaluate the mRNA profiles of TLR1 to 9 in colonic mucosa of UC patients, according to disease activity.
\end{abstract}

Methods: Colonic biopsies were taken from colon during colonoscopy in 51 patients with Ulcerative Colitis and 36 healthy controls. mRNA levels of TLR1 to 9, Tollip, inflammatory cytokines IL6 and TNF were assessed by RT-qPCR with hydrolysis probes. Characterization of TLR9 protein expression was performed by Immunohistochemistry.

Results: Toll-like receptors $T L R 8, T L R 9$, and IL6 mRNA levels were significantly higher in the colonic mucosa from UC patients (both quiescent and active) as compared to healthy individuals ( $p<0.04)$. In the UC patients group the TLR2, TLR4, TLR8 and TLR9 mRNA levels were found to be significantly lower in patients with quiescent disease, as compared to those with active disease $(p<0.05)$, whereas TLR5 showed a trend $(p=0.06)$. IL6 and TNF mRNA levels were significantly higher in the presence of active disease and help to discriminate between quiescent and active disease $(p<0.05)$. Also, $I L 6$ and TNF mRNA positively correlate with TLRs mRNA with the exception for TLR3, with stronger correlations for $T L R 5, T L R 8$, and $T L R 9(p<0.0001)$. TLR9 protein expression was mainly in the lamina propria infiltrate.

Conclusions: This study demonstrates that TLR2, TLR4, TLR8, and TLR9 expression increases in active UC patients, and that the mRNA levels positively correlate with the severity of intestinal inflammation as well as with inflammatory cytokines.

\section{Background}

Ulcerative colitis (UC) is a subtype of Inflammatory Bowel Disease (IBD) characterized by relapsing and chronic inflammation of colonic mucosa [1]. In Mexico, the frequency of new cases of UC has tripled during the last 20 years [2]. The etiology of UC is currently unknown, however inflammation is hypothesized to result from inappropriate activation of mucosal immunity by environmental factors such as gut microbiota

\footnotetext{
* Correspondence: kazuofurusho@hotmail.com

${ }^{2}$ Department of Gastroenterology, Instituto Nacional de Ciencias Médicas y Nutrición Salvador Zubiran, D. F., México

Full list of author information is available at the end of the article
}

[3]. Innate immunity mechanisms involved in recognition of microorganisms are thought implicated in many inflammatory conditions [4]. The Toll-like receptors (TLRs) have been clearly implicated in maintaining gut homeostasis and in the development of IBD [5] although the participation of the whole TLR family in the colonic mucosa from UC patients has not been fully explored.

TLRs are key regulators of the innate immune system in the gut through the induction of pro-inflammatory and immunomodulatory responses in many cell types including immune and epithelial cells [6]. TLR1 to 9 have been reported detectable in human intestine at least in the mRNA levels both in healthy and disease

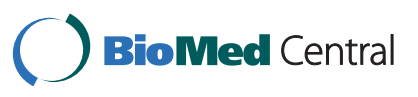


conditions [5]. In particular TLR2 and TLR4 mRNA and protein have been reported to be up-regulated in IBD and in other intestinal inflammatory conditions [7-11]. In a recent study, published by Steenholdt, the TLR 8 expression was found to be up-regulated in isolated cells from the colonic epithelial in patients with Crohn's disease and UC [12]. Also, very recently TLR5 expression was reported down-regulated in patients with UC [13].

To our knowledge, no previous studies have explored the mRNA expression of TLR1 to 9 mRNA in the colonic biopsies from UC patients. Previous studies have focused mainly on the study of TLR2, TLR3 and, TLR4, however, other TLRs expression has not been extensively evaluated in UC patients. In gene expression studies, determination of mRNA levels by quantitative real time PCR (RT-qPCR) is a very robust method that has been used successfully in the IBD field $[14,15]$. Quantification of cytokines and chemokines mRNAs by this method has shown to be as an interesting tool to evaluate IBD disease activity $[14,16,17]$. RT-qPCR also has been traditionally used as gold standard to validate microarray results, due to its good variance coefficient in low level transcripts such as cytokines $[18,19]$.

The aim of this study was to characterize the transcript patterns of TLR1 to 9 in colonic biopsies from UC patients according to activity.

\section{Methods}

\section{Population and tissue samples}

A total of 87 individuals were studied and divided in 3 groups: 1) Active UC ( $\mathrm{n}=30)$; 2$)$ Quiescent UC ( $\mathrm{n}=$ $21)$ and Healthy control group $(n=36)$ table 1 . All UC patients had a confirmed diagnosis of UC by histopathology and were recruited from the Inflammatory Bowel Disease Clinic at the National Institute of Medical Sciences between November 2007 and May 2009. Healthy controls consisted of those individuals who

\begin{tabular}{|c|c|}
\hline Patients Number Gender (M/F) & $24 / 27$ \\
\hline Age (years range) & $41(19-75)$ \\
\hline Disease Duration (1-3/> 3 years) & $10 / 40$ \\
\hline Disease Activity (active/quiescent) & $21 / 30$ \\
\hline Disease Extension: distal colitis/Pancolitis & $21 / 30$ \\
\hline Endoscopic Activity (inactive/mild/moderate/severe) & 20/8/12/11 \\
\hline Histological Activity (inactive/mild/moderate/severe) & $13 / 16 / 12 / 10$ \\
\hline Current therapy: $\mathbf{5}$-aminosalicylate/Corticosteroids & $23 / 18$ \\
\hline Extra-intestinal Manifestations (without/arthritis/other) & $31 / 18 / 8$ \\
\hline Smoking habits (Current smoker/non-smoker/ex-smoker) & $32 / 11 / 8$ \\
\hline \multicolumn{2}{|l|}{ Healthy Control Group } \\
\hline Number of Patients Sex (M/F) & $14 / 22$ \\
\hline Age (years range) & $46(18-64)$ \\
\hline
\end{tabular}

consent to colonoscopy for other reasons such as colorectal cancer screening, weight loss and anaemia. The inclusion criterion was histological normal findings on intestinal biopsy. Details of demographic and clinical characteristics of UC were obtained by a questionnaire, review of records and personal interview. Disease extension was defined by colonoscopy. The disease activity was determined by Mayo score and Riley criteria for endoscopic and histological activity respectively [20].

\section{Ethical considerations}

This work was performed to the principles expressed in the Declaration of Helsinsky. This study was approved by the ethical committee in our hospital and a written informed consent was obtained from all patients and controls.

\section{Sample processing RNA extraction and cDNA synthesis}

All 87 intestinal mucosal biopsies taken from colonoscopy were immediately placed in RNA later (Ambion, Austin, TX, USA) and stored at $-70^{\circ} \mathrm{C}$ until processing. Then RNA isolation from all biopsies was performed with High Pure RNA Tissue Kit (ROCHE, Sciences, Maryland, USA) according to the manufacturer's instructions. The evaluation of RNA integrity, concentration, and purity was done by ribosomal visualizing RNA $18 \mathrm{~S}$ and $28 \mathrm{~S}$ integrity on agarose $1.5 \%$ gels, and by spectrophotometer on NanoDrop 2000 respectively (Thermo Fisher Scientific Lafayette, CO, USA). Duplicate cDNA synthesis was performed from $250 \mathrm{ng}$ of total RNA using random hexamers and the Transcriptor first strand cDNA synthesis kit (ROCHE, Sciences, Maryland, USA).

\section{Real time RT-qPCR}

RT-qPCR analysis was performed using Roche LightCycler 2.0 (ROCHE, Reuskreutz, Swisserland) with LNA hydrolysis probes from the Universal Probe Library Roche (UPL), and intron spanning designed primers (table 2) from Invitrogen (Carlsbad California, USA). One $\mu \mathrm{l}$ of cDNA was amplified with 200nM of primers, $100 \mathrm{nM}$ of UPL probe, with the LighCycler TaqMan ${ }^{\circledR}$ Master (ROCHE, Sciences, Maryland, USA) followed by 45 cycles of $95^{\circ} 10 \mathrm{sec} .60^{\circ} 30$ sec., and $72^{\circ} 1 \mathrm{sec}$. Reference genes RPLPO, ACTB, and $G A P D H$ transcripts were used for relative quantification. For qPCR assays quality control, determination of linearity and reproducibility was evaluated ( $\mathrm{VC}<10 \%)$. The mRNA relative quantification of target genes was conducted using the LightCycler software 4.1, according to the 2- $\Delta \Delta \mathrm{Ct}$ method. The calibrator sample employed was the same patient sample performed in all runs.

\section{Immunohistochemistry}

Samples from six UC patients with and without inflammatory activity were included for TLR9 
Table 2 Primers Designs for qPCR

\begin{tabular}{|c|c|c|c|c|}
\hline Gene & GENEBANK & PRIMERS $\left(5^{\prime}-3^{\prime}\right)$ & Amplicon Size (bp) & PROBE UPL \\
\hline \multirow[t]{2}{*}{$\overline{T L R 1}$} & NM_003263.3 & CCTAGCAGTTATCACAAGCTCAAA & 70 & $\# 79$ \\
\hline & & TCTITCCTTGGGCCATTC & & \\
\hline \multirow[t]{2}{*}{ TLR2 } & NM_003264.3 & CGTTCTCTCAGGTGACTGCTC & 66 & $\# 14$ \\
\hline & & TCTCCTITGGATCCTGCTTG & & \\
\hline \multirow[t]{2}{*}{ TLR3 } & NM_003265.2 & AGTTGTCATCGAATCAAATTAAAGAG & 61 & $\# 80$ \\
\hline & & AATCTTCCAATTGCGTGAAAA & & \\
\hline \multirow[t]{2}{*}{ TLR4 } & NM_138554.2 & CTGCGTGAGACCAGAAAGC & 75 & \#33 \\
\hline & & TTCAGCTCCATGCATTGATAA & & \\
\hline \multirow[t]{2}{*}{ TLR5 } & NM_003268.4 & GACACAATCTCGGCTGACTG & 105 & \#16 \\
\hline & & TCAGGAACATGAACATCAATCTG & & \\
\hline \multirow[t]{2}{*}{ TLR6 } & NM_006068.2 & TGAAACAGTCTCTITTGSGTAAATGC & 72 & \#55 \\
\hline & & CAGAATCCATTTGGGAAAGC & & \\
\hline \multirow[t]{2}{*}{$T L R 7$} & NM_016562.3 & CCAGTGTCTAAAGAACCTGGAAA & 63 & \#5 \\
\hline & & TCAGGGACAGTGGTCAGTTG & & \\
\hline \multirow[t]{2}{*}{$T L R 8$} & NM_138636.2 & AGCACTTCCCTCAGGAAGATT & 62 & $\# 27$ \\
\hline & NM_016610.2 & AGCACCTTCAGATGAGGCATA & & \\
\hline \multirow[t]{2}{*}{ TLR9 } & NM_017442.2 & CCAGACCCTCTGGAGAAGC & 133 & \#81 \\
\hline & & GTAGGAAGGCAGGCAAGGT & & \\
\hline \multirow[t]{2}{*}{ TOLLIP } & NM_019009.2 & TCCCCGCTGGAATAAGGT & 95 & \#86 \\
\hline & & CGTCCATGGAGAAGGCTCT & & \\
\hline \multirow[t]{2}{*}{ TNFA } & NM_000594.2 & CAGCCTCTTCTCCTTCCTGA & 123 & \#29 \\
\hline & & GCCAGAGGGCTGATTAGAGA & & \\
\hline \multirow[t]{2}{*}{126} & NM_000600 & GCCCAGCTATGAACTCCTTCT & 86 & $\# 45$ \\
\hline & & GAAGGCAGCAGGCAACAC & & \\
\hline \multirow[t]{2}{*}{${ }^{*} R P L P O$} & NM_001002.3 & ACAGGGCGACCTGGAAGT & 117 & $\# 32$ \\
\hline & NM_053275.3 & GGATCTGCTGCATCTGCTT & & \\
\hline \multirow[t]{2}{*}{${ }^{*} G A D P H$} & NM_002046.3 & AGCCACATCGCTCAGACAC & 66 & $\# 60$ \\
\hline & & GCCCAATACGACCAAATCC & & \\
\hline \multirow[t]{2}{*}{ ACTB } & ENST00000331789.2 & CAACCGCGAGAAGATGAC & 121 & $560 \mathrm{~nm}$ \\
\hline & & GTCCATCACGATGCCAGT & & \\
\hline
\end{tabular}

Note. TLR8, and RPLPO assays were designed to detect both transcript isoforms, UPL (Universal Probe Library).

Immunohistochemistry. Peroxidase staining of paraffinembedded tissue slides was performed using standard protocols. Briefly, after deparaffinizing and demasking of antigens, endogenous peroxidases were blocked with H2O2. Slides were blocked with 10\% normal serum and were incubated with avidin and biotin. Following incubation with the primary antibody overnight at $4{ }^{\circ} \mathrm{C}$, slides were incubated with the secondary, biotin-conjugated antibody. Next, they were incubated with HRP-streptavidin, followed by incubation with the peroxidase substrate 3'-diaminobenzidine (DAB). In the negative controls, cells were stained omitting the primary antibody.

\section{Statistical Analysis}

Statistical analysis was performed using SPSS Ver. 15 statistical package program. Statistical significance was considered when $\mathrm{p}$ value was $<0.05$. Descriptive statistics were used as means and standard deviations and medians and interquartilar range. Kolmogorov-Smirnoff normality test determined RNA data distribution. Kruskal-Wallis and Mann Whitney U non parametric tests were used to test differences among groups, and Spearman correlation to asses the relationship between TLR1 to 9, TNF and IL6 RNA levels and the endoscopic and histological parameters.

\section{Results}

TLR1 to 9 mRNA profiles in UC compared with Controls

The TLR1 to 9, TOLLIP, and TNF and IL6 mRNAs were detectable and quantifiable by RT-qPCR in intestinal biopsies from UC patients with quiescent and active disease as well as in healthy controls (table 3). TLR4, $T L R 8$, and TLR9 mRNA levels were higher in the overall UC patients compared to healthy controls $(\mathrm{p}<0.04)$ (table 3 ). We found a significantly increased expression of TLR2, TLR4, TLR8, and TLR9 mRNA expression in the colonic mucosa biopsies from patients with active 
Table 3 Transcript levels of TLRs and pro-inflammatory cytokines in colonic mucosa from UC patients and Controls

\begin{tabular}{|c|c|c|c|c|c|c|c|c|}
\hline \multirow[t]{2}{*}{$\begin{array}{l}\text { GENE } \\
\text { mRNA }\end{array}$} & $\begin{array}{c}\text { Control N } \\
=36\end{array}$ & $\begin{array}{c}\text { UC Patients } \mathrm{N} \\
\quad=51\end{array}$ & $\begin{array}{c}\text { UC Quiescent N } \\
\quad=21\end{array}$ & $\begin{array}{c}\text { UC Active N } \\
=31\end{array}$ & $\begin{array}{c}\text { Control vs } \\
\text { UC }\end{array}$ & $\begin{array}{c}\text { Control vs UC } \\
\text { Quiescent }\end{array}$ & $\begin{array}{c}\text { Control vs UC } \\
\text { Active }\end{array}$ & $\begin{array}{c}\text { UC Quiescent vs } \\
\text { Active }\end{array}$ \\
\hline & \multicolumn{4}{|c|}{ Transcript Levels } & \multicolumn{4}{|c|}{$P$ value } \\
\hline$T L R 1$ & $0.75 \pm 0.50$ & $1.12 \pm 1.63$ & $1.33 \pm 2.51$ & $0.98 \pm 0.53$ & 0.26 & 0.64 & 0.13 & 0.11 \\
\hline TLR2 & $0.63 \pm 0.25$ & $1.63 \pm 2.5$ & $0.72 \pm 0.4$ & $2.55 \pm 3.30$ & 0.14 & 0.9 & $\underline{0.001}$ & $\underline{0.002}$ \\
\hline$T L R 3$ & $0.54 \pm 0.25$ & $0.75 \pm 0.5$ & $0.87 \pm 0.60$ & $0.63 \pm 0.39$ & 0.6 & 0.18 & 0.7 & 0.27 \\
\hline TLR4 & $0.64 \pm 0.23$ & $1.3 \pm 0.94$ & $1.01 \pm 0.62$ & $1.55 \pm 1.12$ & $\underline{0.002}$ & $\underline{0.015}$ & $\underline{0.0001}$ & $\underline{0.04}$ \\
\hline TLR5 & $0.94 \pm 0.58$ & $0.86 \pm 0.5$ & $0.71 \pm 0.46$ & $0.96 \pm 0.52$ & 0.75 & 0.14 & 0.55 & $0.06^{*}$ \\
\hline$T L R 6$ & $0.91 \pm 0.61$ & $0.8 \pm 0.67$ & $0.59 \pm 0.36$ & $0.94 \pm 0.79$ & 0.52 & 0.11 & 0.56 & 0.19 \\
\hline$T L R 7$ & $0.71 \pm 0.45$ & $0.62 \pm 0.79$ & $0.77 \pm 1.21$ & $0.52 \pm 0.27$ & 0.86 & 0.14 & 0.13 & 0.82 \\
\hline TLR8 & $1.13 \pm 0.73$ & $1.96 \pm 2.19$ & $0.88 \pm 0.59$ & $2.67 \pm 2.56$ & $\underline{0.04}$ & 0.22 & $\underline{0.001}$ & $\underline{0.0005}$ \\
\hline TLR9 & $0.75 \pm 0.57$ & $1.12 \pm 1.1$ & $0.66 \pm 0.37$ & $1.60 \pm 1.26$ & 0.037 & 0.95 & $\underline{0.004}$ & $\underline{0.006}$ \\
\hline TOLLIP & $0.79 \pm 0.21$ & $0.84 \pm 0.28$ & $0.85 \pm 0.32$ & $0.83 \pm 0.26$ & $\overline{0.41}$ & 0.69 & $\overline{0.82}$ & $\overline{0.86}$ \\
\hline TNF & $0.96 \pm 1.28$ & $0.84 \pm 0.79$ & $0.4 \pm 0.37$ & $1.24 \pm 0.86$ & 0.96 & $\underline{0.01}$ & $\underline{0.023}$ & $<0.001$ \\
\hline IL6 & $1.8 \pm 3.5$ & $8 \pm 19.5$ & $1.6 \pm 3.2$ & $11 \pm 23$ & 0.039 & 0.8 & $<0.001$ & $<0.001$ \\
\hline
\end{tabular}

Transcript levels are shown as means and standard deviations. P with significance are underlined and * for trend.

UC compared with both quiescent UC and healthy controls ( $\mathrm{p} \leq 0.05)$ (table 3). Comparisons between the quiescent group and the control group, only showed a significant up-regulation for TLR4 mRNA levels $(\mathrm{p}=$ 0.04) (table 3), while the TLR2, TLR8 and TLR9 mRNA levels were similar in the healthy control and quiescent UC group (table 3). Interestingly, the TLR5 mRNA levels tend to be lower in the quiescent $\mathrm{UC}$ group as compared to active $\mathrm{UC}(\mathrm{p}=0.06)$ (table 3$)$. The other TLRs (TLR1, TLR3, TLR6 and TLR7) and TOLLIP mRNA levels showed change in gene expression when comparing groups $(\mathrm{p}>0.1)$ (table 3$)$.

Correlation of TLR5, TLR8, TLR9, and IL6 mRNA levels with endoscopic and histological activity

To further evaluate the relation of less studied TLRs mRNA levels in IBD and gut inflammation in UC patients. We evaluated the correlation between TLR5, TLR8, TLR9 and IL6 mRNA expression levels and endoscopic (Figure 1) as well as histological activity (Figure 2) both activity scales were evaluated in a blinded fashion. Comparisons among groups are shown in the figures 1 and 2, TLR5, TLR5 TLR5 and IL6 mRNA levels were higher in the inflammatory active groups ( $\mathrm{p}$ values are shown in the figures). Positive correlations were found for the mRNA levels of TLR5 ( $\mathrm{r}=0.387 ; \mathrm{p}=$ 0.005), TLR8 ( $\mathrm{r}=0.465 ; \mathrm{p}=0.001), \operatorname{TLR} 9(\mathrm{r}=0.288 ; \mathrm{p}$ $=0.04)$, and IL6 ( $\mathrm{r}=0.439 ; \mathrm{p}=0.001)$ with endoscopic activity as shown in Figure 1. On the other hand, the mRNA levels of TLR5, TLR8, TLR9, and IL6 correlation with histological activity, such as TLR5 ( $\mathrm{r}=0.341 ; \mathrm{p}=$ 0.015), TLR8 ( $\mathrm{r}=0.577$; $\mathrm{p}<0.001), T L R 9$ ( $\mathrm{r}=0.428 ; \mathrm{p}$ $=0.002)$, and IL6 ( $\mathrm{r}=0.633 ; \mathrm{p}<0.001)$ as shown in Figure 2. The TLRs mRNA positive correlations with endoscopic and histological activity tend to be significantly higher analysing the subset of patients who did not received any steroid treatment at the moment of the study (overall $\mathrm{r}>0.6 ; \mathrm{p}<0.01$ ).

\section{TLRs mRNA levels correlate with IL6, and TNF mRNA} levels in the colonic mucosa from UC patients

In this study, we also found that in particular IL6 mRNA levels strongly correlate with disease activity. The IL6 mRNA levels showed an important capacity to differentiate between quiescent and active disease (Receiver Operator Curve, AUC = 0.876; p < 0.0001) compared to TNF (Receiver Operator Curve, AUC = $0.700 ; \mathrm{p}<0.0001)$. Therefore, in we explore the correlation of IL6 and TNF mRNA levels as inflammatory markers with the TLRs mRNA levels. We found that IL6 and TNF mRNA levels showed a positive correlation with TLRs (TLR1, TLR2, TLR4, TLR5, TLR6, TLR8 and TLR9) (table 4). The most relevant association was found between IL6 and TLR 8 mRNA levels showing also an $\mathrm{r} 2=0.4626 \mathrm{p}<0.01$ by linear regression analysis.

\section{Mucosa-Infiltrating Immune Cells Are a Major Source of Intestinal TLR9 Expression}

In order to further characterize the cells responsible for TLR9 expression, we determine in situ TLR9 protein expression from intestinal biopsies of UC patients, tissues were immunostained and compared with noninflamed tissue (Figure 3e-f). The percentage of TLR9 immunoreactive cells was higher in UC patients compared to controls. TLR9+ cells were localized mainly in mucosa (Figure 3) lamina propria and perivascular inflammatory infiltrates (Figure $3 \mathrm{~d}$ and $3 \mathrm{e}$ ) but not in goblet cells, crypt lumen or crypt branching, neither submucosa. 


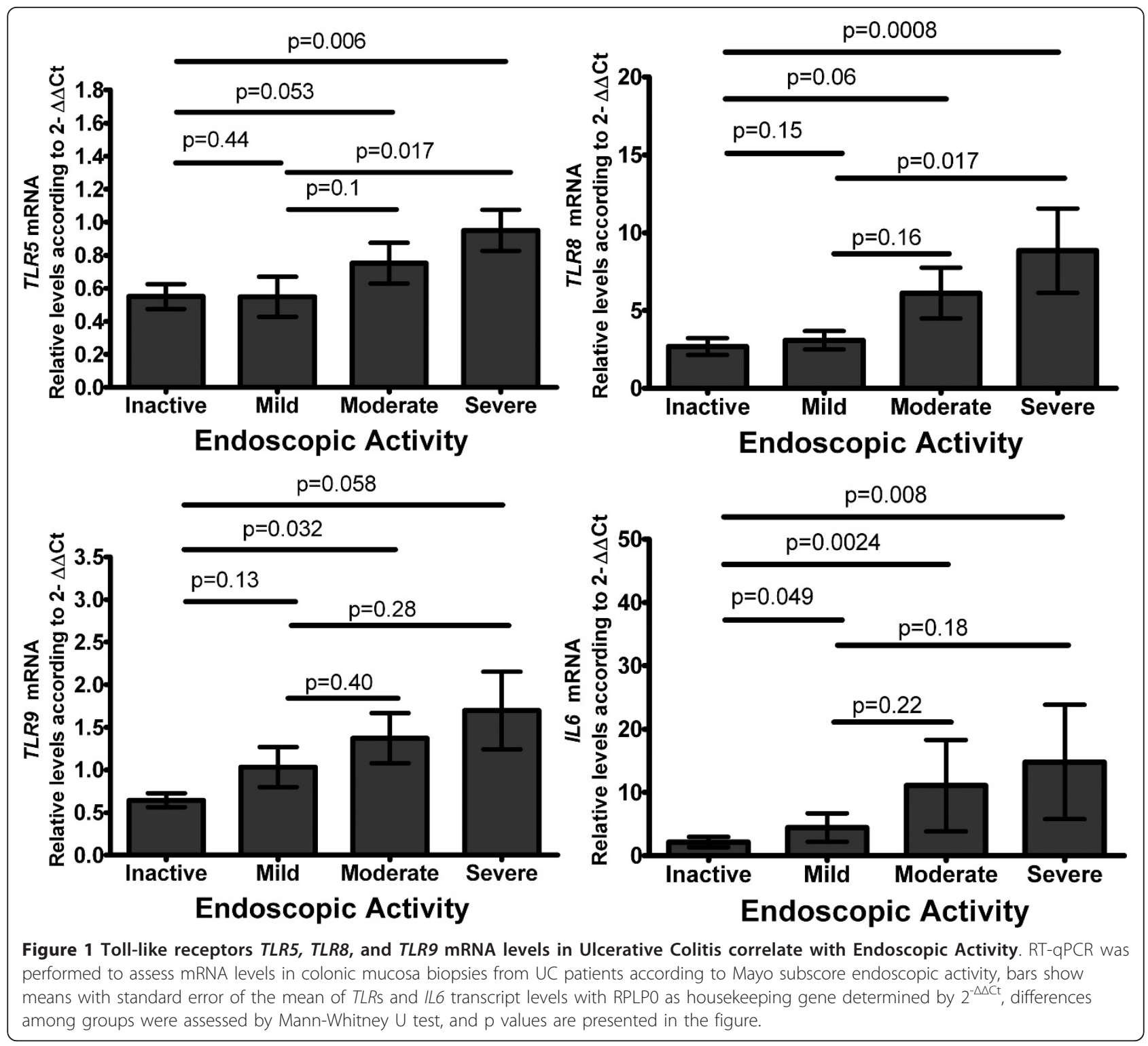

\section{Discussion}

In the present study, we found that gene expression of TLR2, TLR4, TLR8 and TLR9 was substantially upregulated active UC patients. In particular, less studied TLR5, TLR8 and TLR9 gene expression positively correlated with the presence of UC and the severity of endoscopic and histological inflammation. The IL6 and TNF gene expression showed the same trend as TLRs. The other TLRs (TLR1, TLR3, TLR6, TLR7), and TOL$L I P$ mRNA levels were not found to be significantly altered in the presence of active UC. Our results corroborate previously reported results for TLR2 and TLR4 gene expression in IBD $[7,8,11,21]$ and in general for intestinal inflammation such as Celiac Disease and IBS $[9,22]$.
We found also that TLR5 mRNA tends to be up-regulated in active UC compared to UC quiescent disease ( $\mathrm{p}$ $=0.06$ ), but we also found that TLR5 also tends to be down-regulated in UC quiescent disease compared to healthy mucosa colonic controls $(\mathrm{p}=0.14)$. In a previous study, Cario and Podolsky reported no changes of TLR5 expression in the colonic mucosa from IBD patients [7]. Stanislawowski and colleagues found a negative correlation between TLR5 and both macroscopically and microscopically inflammation $[7,13]$. We suspect that this different finding can be possibly due to a regulation of the TLR5 transcript levels by steroids therapy, because we do not found significant Spearman correlations of TLR5 mRNA and disease activity indexes ( $p>0.1$ ) compared to patients treated only with 5-ASA 


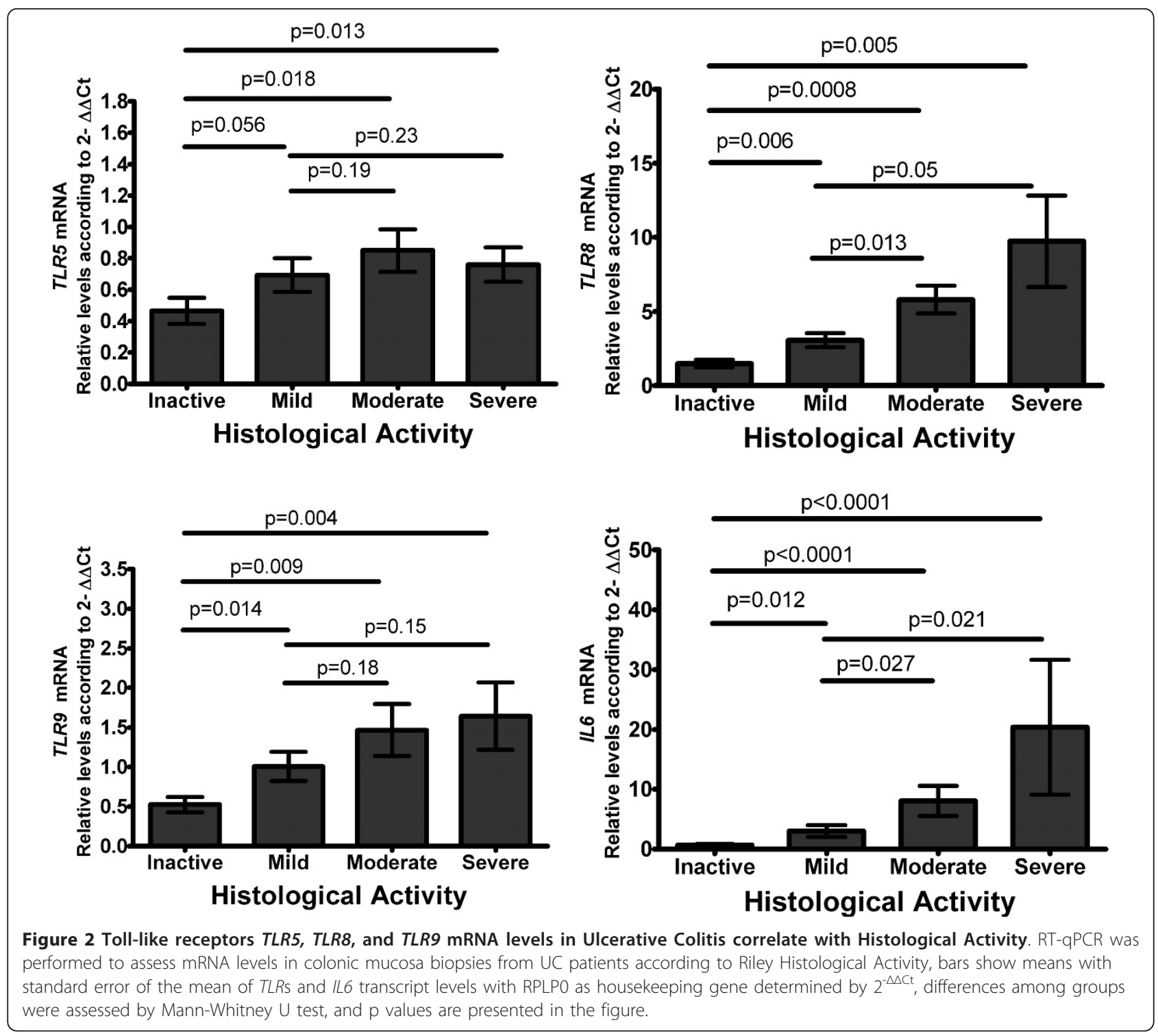

Table 4 Toll-like receptors and Tollip mRNA correlations with IL6 and TNF mRNAs in Rectum mucosa from UC patients

\begin{tabular}{lllll}
\hline Gene Transcript & \multicolumn{3}{c}{ IL6 } & TNF \\
& Rho & $\mathbf{P}$ & Rho & P \\
\hline TLR1 & 0.589 & $<0.001$ & 0.572 & $<0.001$ \\
TLR2 & 0.626 & $<0.001$ & 0.704 & $<0.001$ \\
TLR3 & -0.28 & 0.089 & -0.069 & 0.679 \\
TLR4 & 0.367 & 0.023 & 0.546 & $<0.001$ \\
TLR5 & 0.565 & $<0.001$ & 0.615 & $<0.001$ \\
TLR6 & 0.387 & 0.007 & 0.561 & 0.001 \\
TLR7 & 0.34 & 0.05 & 0.242 & 0.168 \\
TLR8 & 0.681 & $<0.001$ & 0.623 & $<0.001$ \\
TLR9 & 0.583 & $<0.001$ & 0.643 & $<0.001$ \\
TOLLIP & -0.264 & 0.11 & -0.065 & 0.698 \\
\hline
\end{tabular}

$(\mathrm{p}<0.002)$. In addition, our results also show that TLR5 up-regulation is related to inflammation as seen in colectomized UC patients who developed pouchitis [23]. Also, Brint et al. recently found that TLR5 mRNA was up-regulated in colonic biopsies from active Irritable Bowel Syndrome patients [22].

The TLR8 gene expression in colonic mucosa determined by us confirmed the results published by Steenholdt et al. who showed that the TLR8 expression was highly up-regulated in colonic epithelial cells from active UC patients [12]. The functional consequence for TLR8 up-regulation in the gut is unknown, although except for TLR2 all other TLRs in epithelial cells induce proinflammatory signals [5]. TLR 8 induction of IL 8 by ligands in human isolated epithelial cells stimulated has been reported [12]. We suspect that TLR8 up-regulation 


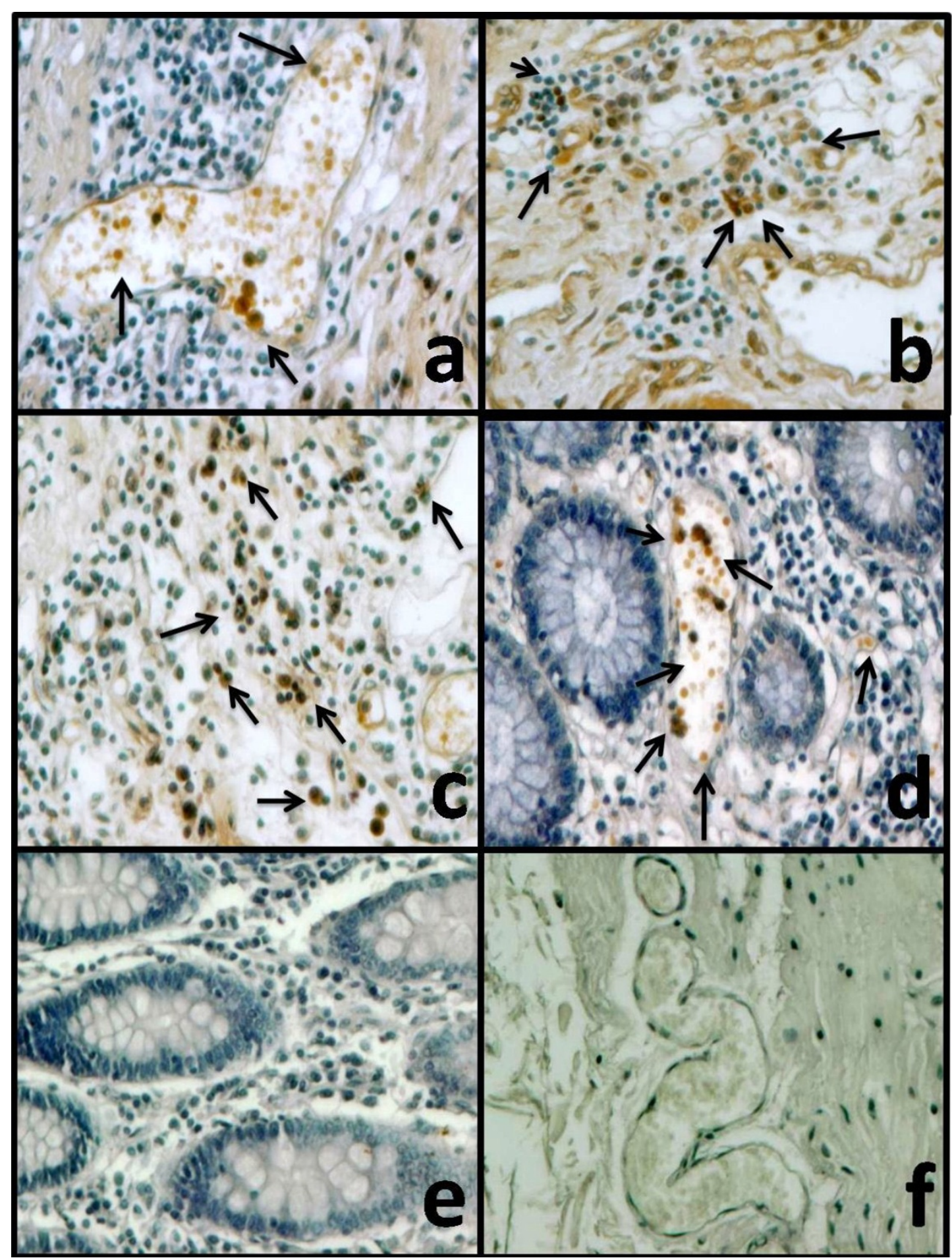

Figure 3 TLR9 increased detection in positive infiltrating immune cells in active UC. Representative immunoperoxidase analysis of TLR9 expression of inflamed colonic tissue from six patients (panel A-D) uninflamed colonic tissue (panel E-F) and taken from a representative patient with UC. In the negative controls (neg. ctrl), the secondary antibody was omitted. Original magnification was $20 \times($ panels A, C, D). 
in colonic epithelial cells may induce an exacerbated inflammatory response against not well studied gut microbiota virus or bacterial RNA resulting from microbiota dysbiosis.

Although for the case TLR9, expression was initially reported down-regulated in inflamed colonic mucosa from IBD patients [24]. On the other hand, we found that TLR9 gene expression was up-regulated in the presence of active UC and compared to healthy mucosa controls [25]. In the present study, we also found that TLR9 mRNA levels positively correlate with disease activity scores in a blinded fashion. Interestingly in a study conducted in the dog IBD form of disease colonic TLR2, TLR4, and TLR9 mRNA levels are up-regulated [26]. Also, for the TLR9 case we decide to corroborate protein expression by immunohistochemistry because of the differing results in determining the protein expression in colonic samples. We found that the most evident source of TLR9 up-regulation levels during inflammation were the mucosal infiltrating cells. In agreement with our results, Pedersen et al. reported very little TLR9 protein expression in isolated colonic epithelial cells assed by western blot [24]. To our knowledge, almost all other studies have analysed TLR9 expression in cell lines [27-29]. Our findings are relevant because previous a previous study reported by Hall et al. showed that Dendritic Cells signalling via TLR9 in response to commensal bacterial DNA inhibits Treg differentiation in the Gut [30]. Also, in vitro TLR9 expression has been reported induced by pathogenic bacterial DNA, in agreement to possible deleterious role of TLR9 signalling in the gut [27]. Finally, TLR9 frequent promoter polymorphisms associated with IBD might up-regulate TLR 9 gene expression [31,32]. We believe that gut inflammation with leukocyte infiltration and dysbiosis both play a role in the up-regulation of TLR9 expression in the colonic mucosa of UC patients.

In order to evaluate the relation between inflammation and TLR gene expression, we also determine the correlations between TLR1 to 9 mRNA expression and mRNA levels of pro-inflammatory cytokines such as TNF and IL6 (Table 4). It is well known that TNF and IL6 mRNA profiles positively correlate with inflammatory activity and especially IL6 can be used as activity marker in UC $[16,17]$. We also found that TLR8 mRNA levels are useful and efficient means to discriminate between active and quiescent UC.

Finally, the main limitations of our study are the lack of assessment of putative regulatory TLRs promoter polymorphisms, and the evaluation of colonic isolated epithelial and lamina propria isolated colonic cells will corroborate functional consequence of Toll-like receptors cross-talk.

\section{Conclusions}

The TLR5, TLR8 and TLR9 gene expression were upregulated in patients with active UC and had a positive correlation with endoscopic and histological activity. The functional consequence of TLRs over-expression in the mucosa from UC patients needs to be further clarified.

\section{Acknowledgements}

FSM had Conacyt (12905) scholarship during the development of this research; this research was funded by the Department of Gastroenterology at the Institute of Medical Sciences and Nutrition Salvador Zubiran (INCMNSZ).

\section{Author details}

'Doctorado en Ciencias Biológicas y de la Salud, Universidad Autónoma Metropolitana, D.F., México. ${ }^{2}$ Department of Gastroenterology, Instituto Nacional de Ciencias Médicas y Nutrición Salvador Zubiran, D. F., México. ${ }^{3}$ Departament of Endoscopy, Instituto Nacional de Ciencias Médicas y Nutrición Salvador Zubiran, D. F., México. ${ }^{4}$ Fundación Clínica Médica Sur, Puente de Piedra 150, D. F., México. ${ }^{5}$ Department of Health Care. Universidad Autónoma Metropolitana, D.F., México. ${ }^{6}$ Department of Immunology. Instituto Nacional de Cardiología "Ignacio Chávez", D. F., México.

\section{Authors' contributions}

All authors read and approved the final manuscript; FSM participate during the sample processing, performed RT-qPCR analysis for TLR mRNA levels and prepared the manuscript. GFC participate during the sample collecting, processing, RT-qPCR analysis for cytokine transcript level quantification and TLR9 Immunohistochemistry. MAVR participate during the sample recollecting, processing, and non-colitis control characterization. EMP participated during the sample recollecting and data analysis. EJM participate during the sample recollecting and data analysis. RBZ assessed clinical and endoscopic analysis and diagnostics and sampling procedures. MU did critical reviewing and guiding and data analysis. RB participated in critical reviewing and data discussion and analysis. ADL critical reviewing and bibliographic analysis, JKYF designed and provided the research idea, directed, reassessed both clinical and histological diagnostic, and coordinate the manuscript editing.

\section{Competing interests}

The authors declare that they have no competing interests.

Received: 14 October 2010 Accepted: 20 December 2011 Published: 20 December 2011

\section{References}

1. Podolsky DK: Inflammatory bowel disease. N Engl J Med 2002, 347(6):417-429.

2. Yamamoto-Furusho JK: Clinical epidemiology of ulcerative colitis in Mexico: a single hospital-based study in a 20 -year period (1987-2006). J Clin Gastroenterol 2009, 43(3):221-224.

3. Xavier RJ, Podolsky DK: Unravelling the pathogenesis of inflammatory bowel disease. Nature 2007, 448(7152):427-434.

4. Drexler SK, Foxwell BM: The role of toll-like receptors in chronic inflammation. Int J Biochem Cell Biol 2010, 42(4):506-518.

5. Abreu MT: Toll-like receptor signalling in the intestinal epithelium: how bacterial recognition shapes intestinal function. Nat Rev Immunol 2010, 10(2):131-144.

6. Akira S, Takeda K: Toll-like receptor signalling. Nat Rev Immunol 2004, 4(7):499-511.

7. Cario E, Podolsky DK: Differential alteration in intestinal epithelial cell expression of toll-like receptor 3 (TLR3) and TLR4 in inflammatory bowel disease. Infect Immun 2000, 68(12):7010-7017.

8. Hausmann M, Kiessling S, Mestermann S, Webb G, Spottl T, Andus T, Scholmerich J, Herfarth H, Ray K, Falk W, et al: Toll-like receptors 2 and 4 
are up-regulated during intestinal inflammation. Gastroenterology 2002, 122(7):1987-2000.

9. Szebeni B, Veres G, Dezsofi A, Rusai K, Vannay A, Bokodi G, Vasarhelyi B, Korponay-Szabo IR, Tulassay T, Arato A: Increased mucosal expression of Toll-like receptor (TLR)2 and TLR4 in coeliac disease. J Pediatr Gastroenterol Nutr 2007, 45(2):187-193.

10. Frolova L, Drastich P, Rossmann P, Klimesova K, Tlaskalova-Hogenova H: Expression of Toll-like receptor 2 (TLR2), TLR4, and CD14 in biopsy samples of patients with inflammatory bowel diseases: upregulated expression of TLR2 in terminal ileum of patients with ulcerative colitis. J Histochem Cytochem 2008, 56(3):267-274.

11. Szebeni B, Veres G, Dezsofi A, Rusai K, Vannay A, Mraz M, Majorova E, Arato A: Increased expression of Toll-like receptor (TLR) 2 and TLR4 in the colonic mucosa of children with inflammatory bowel disease. Clin Exp Immunol 2008, 151(1):34-41.

12. Steenholdt C, Andresen L, Pedersen G, Hansen A, Brynskov J: Expression and function of toll-like receptor 8 and Tollip in colonic epithelial cells from patients with inflammatory bowel disease. Scand J Gastroenterol 2009, 44(2):195-204.

13. Stanislawowski M, Wierzbicki PM, Golab A, Adrych K, Kartanowicz D, Wypych J, Godlewski J, Smoczynski M, Kmiec Z: Decreased Toll-like receptor-5 (TLR-5) expression in the mucosa of ulcerative colitis patients. J Physiol Pharmacol 2009, 60(Suppl 4):71-75.

14. Zahn A, Giese T, Karner M, Braun A, Hinz U, Stremmel W, Ehehalt R: Transcript levels of different cytokines and chemokines correlate with clinical and endoscopic activity in ulcerative colitis. BMC Gastroenterol 2009, 9:13.

15. Eriksson A, Flach CF, Lindgren A, Kvifors E, Lange S: Five mucosal transcripts of interest in ulcerative colitis identified by quantitative realtime PCR: a prospective study. BMC Gastroenterol 2008, 8:34.

16. Matsuda R, Koide T, Tokoro C, Yamamoto T, Godai T, Morohashi T, Fujita Y, Takahashi D, Kawana I, Suzuki S, et al: Quantitive cytokine mRNA expression profiles in the colonic mucosa of patients with steroid naive ulcerative colitis during active and quiescent disease. Inflamm Bowel Dis 2009, 15(3):328-334.

17. Fonseca-Camarillo G, Villeda-Ramirez M, Sanchez-Munoz F, Barreto-Zuniga R, Dominguez-Lopez A, Uribe-Esquivel M, Yamamoto-Furusho J: [IL-6 and TNF-a gene expression in the rectal mucosal of patients with chronic idiopathic ulcerative colitis and controls.]. Rev Gastroenterol Mex 2009, 74(4):334-340.

18. Noble CL, Abbas AR, Cornelius J, Lees CW, Ho GT, Toy K, Modrusan Z, Pal N, Zhong $F$, Chalasani $S$, et al: Regional variation in gene expression in the healthy colon is dysregulated in ulcerative colitis. Gut 2008, 57(10):1398-1405.

19. Bustin SA, Dorudi $\mathrm{S}$ : The value of microarray techniques for quantitative gene profiling in molecular diagnostics. Trends Mol Med 2002, 8(6):269-272.

20. Riley SA, Mani V, Goodman MJ, Herd ME, Dutt S, Turnberg LA: Comparison of delayed release 5 aminosalicylic acid (mesalazine) and sulphasalazine in the treatment of mild to moderate ulcerative colitis relapse. Gut 1988, 29(5):669-674.

21. Toiyama Y, Araki T, Yoshiyama S, Hiro J, Miki C, Kusunoki M: The expression patterns of Toll-like receptors in the ileal pouch mucosa of postoperative ulcerative colitis patients. Surg Today 2006, 36(3):287-290.

22. Brint EK, Macsharry J, Fanning A, Shanahan F, Quigley EM: Differential expression of toll-like receptors in patients with irritable bowel syndrome. Am J Gastroenterol 2011, 106(2):329-336.

23. Heuschen G, Leowardi C, Hinz U, Autschbach F, Stallmach A, Herfarth C, Heuschen UA: Differential expression of toll-like receptor 3 and 5 in ileal pouch mucosa of ulcerative colitis patients. Int J Colorectal Dis 2007, 22(3):293-301.

24. Pedersen G, Andresen L, Matthiessen MW, Rask-Madsen J, Brynskov J: Expression of Toll-like receptor 9 and response to bacterial CpG oligodeoxynucleotides in human intestinal epithelium. Clin Exp Immunol 2005, 141(2):298-306

25. Sanchez-Munoz F, Fonseca-Camarillo GC, Villeda-Ramirez MA, BarretoZuniga R, Bojalil R, Dominguez-Lopez A, Uribe M, Yamamoto-Furusho JK: TLR9 mRNA expression is upregulated in patients with active ulcerative colitis. Inflamm Bowel Dis 2010, 16(8):1267-1268.
26. Burgener IA, Konig A, Allenspach K, Sauter SN, Boisclair J, Doherr MG, Jungi TW: Upregulation of toll-like receptors in chronic enteropathies in dogs. J Vet Intern Med 2008, 22(3):553-560.

27. Ewaschuk JB, Backer JL, Churchill TA, Obermeier F, Krause DO, Madsen KL: Surface expression of Toll-like receptor 9 is upregulated on intestinal epithelial cells in response to pathogenic bacterial DNA. Infect Immun 2007, 75(5):2572-2579.

28. Lee J, Mo JH, Katakura K, Alkalay I, Rucker AN, Liu YT, Lee HK, Shen C, Cojocaru G, Shenouda S, et al: Maintenance of colonic homeostasis by distinctive apical TLR9 signalling in intestinal epithelial cells. Nat Cell Biol 2006, 8(12):1327-1336.

29. Akhtar M, Watson JL, Nazli A, McKay DM: Bacterial DNA evokes epithelial IL-8 production by a MAPK-dependent, NF-kappaB-independent pathway. FASEB J 2003, 17(10):1319-1321.

30. Hall JA, Bouladoux N, Sun CM, Wohlfert EA, Blank RB, Zhu Q, Grigg ME, Berzofsky JA, Belkaid Y: Commensal DNA limits regulatory $T$ cell conversion and is a natural adjuvant of intestinal immune responses. Immunity 2008, 29(4):637-649.

31. Fuse K, Katakura K, Sakamoto N, Ohira H: Toll-like receptor 9 gene mutations and polymorphisms in Japanese ulcerative colitis patients. World J Gastroenterol 2010, 16(46):5815-5821.

32. Lange NE, Zhou X, Lasky-Su J, Himes BE, Lazarus R, Soto-Quiros M, Avila L, Celedon JC, Hawrylowicz CM, Raby BA, et al: Comprehensive genetic assessment of a functional TLR9 promoter polymorphism: no replicable association with asthma or asthma-related phenotypes. BMC Med Genet 2011, 12:26.

\section{Pre-publication history}

The pre-publication history for this paper can be accessed here: http://www.biomedcentral.com/1471-230X/11/138/prepub

doi:10.1186/1471-230X-11-138

Cite this article as: Sánchez-Muñoz et al:: Transcript levels of Toll-Like receptors 5, 8 and 9 correlate with inflammatory activity in Ulcerative Colitis. BMC Gastroenterology 2011 11:138.

\section{Submit your next manuscript to BioMed Central and take full advantage of:}

- Convenient online submission

- Thorough peer review

- No space constraints or color figure charges

- Immediate publication on acceptance

- Inclusion in PubMed, CAS, Scopus and Google Scholar

- Research which is freely available for redistribution

Submit your manuscript at www.biomedcentral.com/submit
Ciomed Central 